\title{
Configurações
}

Revista de sociologia

\section{Introdução - Arte política e social: discursos e práticas}

Teresa Mora, Francesca Rayner e Natália Azevedo

\section{(2) OpenEdition}

\section{Edição electrónica}

URL: http://journals.openedition.org/configuracoes/6262

DOI: 10.4000/configuracoes.6262

ISSN: 2182-7419

\section{Editora}

Centro de Investigação em Ciências Sociais

\section{Edição impressa}

Paginação: 7-10

ISSN: 1646-5075

\section{Refêrencia eletrónica}

Teresa Mora, Francesca Rayner e Natália Azevedo, «Introdução - Arte política e social: discursos e práticas », Configurações [Online], 22 | 2018, posto online no dia 22 dezembro 2018, consultado o 30 abril 2019. URL : http://journals.openedition.org/configuracoes/6262 ; DOI : 10.4000/ configuracoes.6262 
Mora, Teresa; Rayner, Francesca; Azevedo, Natália - Introdução - Arte política e social: discursos e práticas. Configurações, vol. 22, 2018, pp. 7-10.

\title{
Introdução - Arte política e social: discursos e práticas
}

\author{
TERESA MORA* \\ Centro Interdisciplinar de Ciências Sociais -Universidade do Minho \\ FRANCESCA RAYNER ** \\ ILCH - Universidade do Minho \\ NATÁLIA AZEVEDO*** \\ Faculdade de Letras - Universidade do Porto
}

Tem sido prática da revista Configurações entrecruzar contributos provenientes das várias ciências sociais. O número 22 traz aos leitores um conjunto de artigos que resultam, também, e sobretudo, da opção de abrir o tema da arte política e social aos estudos artísticos.

Desde o final dos anos 1990, no contexto mundial, e em particular na Europa, a arte política tem vindo a reavivar-se enquanto discurso e prática de questionamento dos modos de organização da vida coletiva nas suas estruturas de poder e de dominação, quer por interlocutores do mundo científico, quer por instâncias e agentes do mundo da(s) arte(s).

$\mathrm{Na}$ sua dimensão social (ou relacional), a arte intervém junto de indivíduos, grupos, ou comunidades, em escalas simbólicas e territoriais diversas - no espaço público, na rua, no bairro, na escola, na prisão, na casa-abrigo, no hospital, na comunidade terapêutica -, em modalidades de agenciamento várias (de sensibilização, de participação, de cidadania, de sustentabilidade), com o objetivo social de melhorar situações reais de pessoas e de populações, em contextos (políticos, económicos e culturais) de transgressão, segregação, exclusão, guetização, estigmatização, discriminação, periferialização, privação, degradação.

Valorizados em várias escalas de poder (municipal, nacional, supranacional) como um outro meio para tentar minorar esses "problemas sociais", os projetos artístico-culturais configuram-se, também, enquanto objetos, instrumentos e resultados de políticas públicas.

\footnotetext{
*E-mail: tmora@ics.uminho.pt

**E-mail: frayner@ilch.uminho.pt

***E-mail: nazevedo@letras.up.pt
} 
Entre artistas e cientistas contraem-se práticas de aproximação, diálogo e cruzamento, na reflexão (teórica), na ação (metodológica e técnica), na intervenção (social). Em ruptura com a tradicional divisão institucional do trabalho arte/ciência, as práticas colaborativas que cientistas sociais e artistas realizam entre si põem em causa, por um lado, uma visão normativa da prática da(s) ciência(s) assente no pressuposto de uma clara demarcação entre os seus procedimentos metódicos e discursivos e os que configuram a prática da(s) arte(s); e, por outro, um pressuposto distintivo incorporado pelo mundo da(s) arte(s) quanto à inviabilidade dos discursos e das práticas reflexivas e interventivas das ciências sociais e humanas sobre este mesmo mundo.

Os artigos reunidos neste número pretendem contribuir para a diversificação do conhecimento da arte política e social ao trazerem aos leitores um leque variado de abordagens neste campo temático. Com incidência disciplinar e interdisciplinar em algumas das problemáticas anteriormente enunciadas, e passando por incursões em vários contextos empíricos (Portugal, Brasil, Colômbia, Equador), os artigos aqui dispostos vão convocando diversas linguagens artísticas (teatro, literatura, artes plásticas, fotografia, design). Mas, acima de tudo, apresentam-se como tendo sido escritos a partir de alguns dos muitos lugares discursivos e práticos que hoje configuram a arte política e social. Assim, Configurações 22, a par de persistir em veicular os contributos de investigações científico-sociais sustentadas diretamente por empiria e/ou apoiadas em referentes empíricos de espessura histórica (neste caso, da arte política e social), apresenta-as como reflexões, preocupações e intervenções que - em paridade com os contributos aqui alicerçados nos estudos artísticos e/ou sustentados por fruições, práticas e experiências artísticas - se configuram inseparáveis de envolvências pessoais, sociais e políticas afetas ao carácter movente dos percursos académicos, cívicos e profissionais dos seus autores, projetados, no caso, no campo dos estudos da(s) arte(s).

No primeiro artigo, Ana María Castro Sánchez analisa a contribuição das lutas feministas para a democratização da política e dos cânones artísticos no contexto colombiano. A partir de uma visão mais alargada da política, que integra experiências consideradas privadas e íntimas, descreve a ocupação de espaços não-tradicionais pelas lutas feministas e o tornar visível da sua opressão através de manifestações artísticas. Enquanto as representações simbólicas de uma sociedade tendem a reforçar ideologias hegemónicas, as artistas feministas contestam estas representações, seja através das instituições culturais, na rua ou no seu próprio corpo. Sánchez complementa a sua análise teórica com exemplos práticos de artivistas feministas que acompanham as lutas políticas tais como a colectiva Féminas Festivas e artistas que abordam temas feministas no seu trabalho como Ana María Villate Marín.

Rui Mourão questiona a relação da arte com noções de verdade. Através de uma identificação ao longo do artigo de momentos históricos de trans-verdade, 
anti-verdade e pós-verdade nos movimentos artísticos, critica o momento atual pela sua ênfase sobre o distanciamento crítico, a sua desvalorização das emoções e negação da possibilidade de entrega ao objeto artístico e ao outro. Propõe um novo paradigma de bio-verdade, um processo laboratorial de exploração de metáforas e do corpo como forma de reestabelecer uma relação entre a arte e a verdade sem reforçar verdades absolutas convenientes aos regimes políticos vigentes e à comodificação do objeto artístico nos mercados internacionais.

Teresa Mora e Ana Filipa Oliveira, por sua vez, apresentam os resultados de um estudo exploratório sobre o projeto de arte e comunidade AMAReMAR (2016-2017), desenvolvido por artistas com residentes de dois bairros de habitação social da cidade de Esposende, Portugal, e enquadrado por técnicos municipais. Em contexto de observação participante e com base no caderno de planeamento e notas da artista/formadora da oficina de teatro, as autoras expõem três reportórios metódicos acionados nesse contexto de interação: recursos de abertura identitária, recursos de invenção de um lugar comum (o próprio objeto artístico) e recursos de uma ética de reconhecimento. Recursos estes que consideram ser expressivos de um processo de descolagem simbólica dos participantes-residentes dos dois bairros da categoria desvalorizadora da exclusão social.

Rita Miranda, no seu artigo "A função do teatro no contexto do congelamento da cultura em São Paulo, Brasil”, enquadra a relação entre o contexto da prática teatral na cidade de São Paulo e o contexto dos apoios financeiros municipais à cultura. Tal relação padroniza-se em 2017, ano de referência da análise, numa descontinuidade entre projetos e recursos que tende a valorizar a necessidade quer do discurso político das, e pelas, artes - o teatro como arte política - quer de atitudes de cidadania crítica face ao poder político, este último em crise na sociedade brasileira contemporânea. Preocupações estas discutidas pela autora a partir, não de uma empiria científica, mas das suas vivências artísticas enquanto ator social.

Até que ponto pode a arte teatral colocar-se de fora da lógica de poder inerente a um esquema de produção de sentido representacional? Com esta interrogação de partida, Arthur Belloni ensaia uma certa linha de continuidade antirepresentacional entre três tendências: a estética da presença e da experiência patentes no teatro "pré-trágico" (que antecede a afirmação institucional da tragédia como teatro de representação de conflitos); o teatro "menor" de Carmelo Bene; e a corrente "energética" do teatro contemporâneo. Através deste percurso, o autor leva-nos a reconhecer que a desancoragem dos elementos cénicos de uma base representacional é condição para um teatro de intensidades, na sua conexão com uma economia pulsional de resistência à construção cénica do tema e do sujeito. Por conseguinte, o autor discorre em ruptura política com a encenação do poder da representação como traço dominador da arte teatral.

Susana Noronha aborda um conjunto de projetos sobre experiências de cancro, co-criados por mulheres e homens portugueses, tais como "Retrato de 
mim" (2011) “Nu enfermo" (2012), “Na Minha Pele" (2016) ou "Passar das marcas” (2017). Nestas e noutras exposições artísticas da intimidade oncológica (fotografias, vídeos, desenhos), estão compreendidos testemunhos visuais e orais de mulheres e homens com cancro que ancoram ações de consciencialização, desestigmatização, mobilização e resistência à doença. Partindo do lugar discursivo da ciência social, a autora demonstra que o conhecimento incorporado de quem vive a doença oncológica, se transformado em arte, partilhado, e publicamente divulgado, abre para um entendimento mais próximo, mais informado e mais justo do cancro e da pessoa doente.

Por seu turno, e a partir de um outro tipo de relação - a do direito e da literatura - Rina Pazos exercita uma abordagem interdisciplinar entre a norma jurídica e a norma cultural, procurando proximidades e influências entre os dois tipos de documentos, com particular destaque para as possíveis incidências da literatura na criação de normas jurídicas no Equador. A título ilustrativo, e com base numa análise empírica, a autora enquadra o artigo 57 da Constituição da República Equatoriana a partir de dois enfoques: o das influências que o mesmo tem sobre a produção literária de algumas obras de autores equatorianos - perspetiva artística sobre o texto jurídico; e o dos reflexos da cultura popular local que o mesmo texto jurídico alberga enquanto narrativa cultural. Por outras palavras, e ao consagrar os direitos coletivos dos povos e nacionalidades indígenas, o referido texto jurídico torna centrais no espaço público grupos culturais desprovidos de poder(es).

A concluir este número, Eduardo Pedreiro, lembra-nos que a visão tem ocupado um lugar privilegiado na experiência e compreensão ocidental do mundo, salientando que a condição de exterioridade do sujeito visual tem sido, aliás, ampliada pelos media e as tecnologias digitais com a consequente perda do sentido íntimo associada à desvalorização do tato. Em contra-ponto, o autor leva-nos a reconhecer a complexidade da experiência enquanto processo multissensorial. Conduz-nos, de seguida, ao conceito de público-interator, ou de ator envolvido na experienciação da obra (diferentemente do público-observador). Pela ótica da experiência sensorial em arte e design, tomamos conhecimento de trabalhos artísticos que em declinações várias - materializando sentidos (Tolaas), associando sentidos e sensações (Oiticica; Cardiff e Miller), ou trabalhando a transferência de sentidos (Harbisson; Cardiff) - fazem da "estética relacional" (conceito de Bourriaud) uma prática sensorial. 